\title{
ПРОМИСЛОВИЙ ТРАНСПОРТ
}

\author{
УДК 656.613
}

\author{
О. В. ЩЕРБИНА ${ }^{1 *}$ А. Г. ШИБАЕВ ${ }^{2 *}$
}

${ }^{1 *}$ Каф. «Эксплуатация флота и технологии морских перевозок», Одесский национальный морской университет, ул. Мечникова, 34, Одесса, Украина, 65011, тел.+38 (093) 05357 02, эл. почта olahome@i.ua, ORCID 0000-0001-5029-6098

${ }^{2 *}$ Каф. «Эксплуатация флота и технологии морских перевозок», Одесский национальный морской университет, ул. Мечникова, 34, Одесса, Украина, 65011, тел. (048) 72831 24, эл. почта cafmp@i.ua, ORCID 0000-0002-9886-6069

\section{ЭВРИСТИЧЕСКИЙ МЕТОД ОТБОРА СУДОВ ДЛЯ СОГЛАСОВАННОЙ РАБОТЫ ВОДНОГО ТРАНСПОРТА}

Цель. В настоящем исследовании необходимо рассмотреть формирование методики отбора судов при согласованной работе морского и речного транспорта с применением эвристического подхода. Методика. Для реализации поставленной в исследовании цели авторами был проведен анализ отечественных и зарубежных литературных источников по теме работы, изучена специфика и условия эффективной работы морских монокорпусных судов и составных баржебуксирных судов. Результаты. На основании результатов анализа были сформулированы методы эвристики, обеспечивающие выбор типоразмеров баржебуксирных судов смешанного плавания «река-море» из приоритетного ряда судов наличного флота. Предложенный подход позволяет выполнить отбор судов, в большей степени соответствующих установленной схеме работы. Рациональные сочетания технико-эксплуатационных характеристик таких пар, как «баржи и буксир», «баржебуксирное судно и морское судно», «баржебуксирное судно и ограничивающие характеристики района плавания», являются предпосылкой к увеличению прибыли судоходной компании за счет увеличения провозной способности судов. Научная новизна. Авторами впервые был применен эвристический подход к отбору баржебуксирных и морских судов для согласованной работы с выполнением грузовых операций на рейде устьевого порта при перевозке массовых грузов. В основу подхода положен подбор рационального соотношения технико-эксплуатационных характеристик барж и буксиров. Предложенный подход позволяет определить наилучшее сочетание типоразмеров судов при организации совместной роботы морского и речного транспорта. При этом обеспечивается непрерывность процесса перевозки грузов, следующих из морских портов в речные, расположенные в глубине страны (и в обратном направлении). Практическая значимость. Представленная методика является логическим продолжением цикла работ, выполненных авторами. Полученные результаты также будут применены в последующих личных исследовательских разработках. Кроме того, представленное исследование будет полезным для судоходных компаний, оперирующих баржебуксирным флотом. Также данная методика может быть внедрена в учебный процесс транспортных высших учебных заведений при изучении соответствующих дисциплин.

Ключевые слова: морские и баржебуксирные суда; рейдовая перегрузка; отбор; эвристический подход

\section{Введение}

Одним из вариантов согласованной работы морского и речного флота является организация процесса перевозки грузов, следующих по внутренним водным путям на баржебуксирных судах (ББС), и рейдовой перегрузки непосредственно на морское монокорпусное судно. Такая организация транспортного процесса исключает операции складирования в порту и, как следствие, необходимость хранения грузов для накопления судовой партии. Преимущество такой технологии заключается в том, что грузовые операции в устьевых портах могут выполняться на рейде, где глубины позволяют использовать морские суда большей грузоподъемности.

Известно [1, 6], что эффективность перевозок грузов ББС зависит от рационального использования технических средств. Поскольку работа ББС предполагает формирование соста- 
ва из буксира и нескольких барж, то для обеспечения непрерывности транспортного процесса перевозки грузов при взаимодействии речного и морского транспорта возможно варьирование количеством и технико-эксплуатационными характеристиками (ТЭХ) структурных элементов ББС.

Задача отбора типоразмера ББС является одной из задач организации транспортного процесса, которая предполагает подбор типоразмера судна из возможных вариантов, наилучшим образом соответствующего условиям предстоящей работы. Задача формирования множества вариантов типоразмеров ББС для заданных условий эксплуатации представлена в работе [5].

Таким образом, задача отбора типоразмера ББС из множества возможных, наилучшим образом соответствующего схеме предстоящего рейса, является актуальной.

Анализ литературных данных и постановка проблем. Начало научного обоснования отечественной практики баржебуксирных перевозок судами (ББП) приходится на 20-30 гг. и достигла своего пика к 70-80 гг. ХX ст [3]. Однако, повышенный интерес к ББП в последние десятилетия, обоснованный в работах $[1,6]$, требует совершенствования теоретических основ организации работы ББС с учетом современных условий рынка и текущих технических возможностей, в том числе в судостроении, гидротехнике и пр.

Основы организации работы ББС были разработаны еще в советское время в пиковый период развития ББП и отображены в работах таких ученых, как: М. С. Терятников, А. А. Союзов, А. П. Ирхин, В. К. Щепетов, В. П. Зачесов, Н. А. Юмин, и др. Например, рассмотрены задачи отбора ББС для работы на линиях по критериям оптимальности финансовых показателей и провозной способности судов [2]. Однако, поставленная авторами задача не отражает особенности организации совместной работы ББС и морских судов, учет которых позволит сократить непроизводственные простои флота. Кроме того, в предложенной модели авторами не учитываются ограничения на трассе следования, оказывающие влияние на типоразмер ББС.

В настоящее время исследуются отдельные проблемы, преимущественно носящие инженерно-технический характер эксплуатации ББС в области судостроения и судовождения $[1,13]$.

В отечественных трудах ББП практически не рассматриваются. Но в работе [1] представлен частный случай оценки эффективности эксплуатации баржебуксирного состава «Днепро-макс» класса в сравнении с сухогрузными судами, однако не отображающий общие организационные принципы отбора судов для ББП. Также изложена методика выбора варианта организации работы определенных типов ББС по представленным схемам эксплуатации составов с рейдовой перегрузкой на морские суда. Однако автором не определено условие принятия решения по отбору судов для освоения грузопотока.

Кроме обозначенных областей судостроения и судовождения, зарубежные работы также направлены на исследования в следующих направлениях:

- стратегического развития смешанных перевозок «река-море» в целом, в том числе ББП $[9,10,12,14,15]$;

- интермодальных контейнерных перевозок $[8,11]$.

Так, в работах $[8,11]$ изложены методики построения интермодальной сети обслуживания линий при перевозке контейнеров на баржах.

В работах $[1,9,10]$ представлены методики выбора судна для плавания по маршруту «рекаморе» по экономическим показателям работы судов. При решении поставленной задачи в работах $[9,10]$ выбираются суда и схемы их работы, исходя из представленных в них ограничений.

Таким образом, из анализа приведённых источников видно, что вопросам организации работы ББС при перевозке массовых грузов, а также вопросам согласованной работы морских судов и ББС не уделено должного внимания. Особый интерес вызывают, прежде всего, вопросы, связанные с отбором ББС для организации их работы без закрепления тяги (буксира) за тоннажем (баржами) при рейдовой перегрузке на морские суда.

\section{Цель}

Целью настоящего исследования является формирование методики отбора судов при согласованной работе морского и речного транспорта с применением эвристического подхода.

Исходя из цели, поставлены следующие за- 
дачи исследования:

1) изучение специфики работы судов при взаимодействии морского и речного транспорта; боты;

2)определение условия их эффективной ра-

3)формулирование методов эвристики, обеспечивающие выбор типоразмеров ББС, в большей степени соответствующего установленной схеме работы за счет рационального сочетания ТЭХ барж и буксиров.

Материаль и методы исследования. Для реализации цели, поставленной в исследовании, разработан эвристический подход, который обеспечивает достаточный по отношению к исходной информации уровень достоверности. Кроме того, время, необходимое на решение задачи эвристическим методом, в отличие от задач, основанных на строгих методах оптимизации, в несколько десятков раз меньше. Эвристический подход позволяет сочетать точные математические приемы с процедурами, основанными на интуиции и опыте решения задач этого класса [4].

Таким образом, разработка эвристического подхода для отбора технических средств речных и морских судов при рейдовой перегрузке, является актуальной.

\section{Методика}

Предложенный подход основан на ниже следующих принципах организации работы ББС:

1. Лучшим вариантом организации работы ББС является принцип «вертушки» [1], который предполагает наличие в портах отправления и назначения по одной барже (либо готовых к отправлению, либо находящихся под грузообработкой). При необходимости в схему может быть включен промежуточный порт. Таким образом, при описанном варианте ББС «1 букир+3 баржи» один буксир работает совместно с тремя комплектами барж. В международной практике применяются и другие варианты ББС [7].

2. Буксир, как составная часть ББС, представляет собой его наиболее дорогостоящую часть. Поэтому из двух возможных вариантов организации работы буксира: буксир ожидает погрузку (выгрузку) баржи, с которой пришел в порт (вариант 1), и буксир продолжает движение с баржей, которая уже находится в этом порту (вариант 2) - предпочтенье отдается последнему, поскольку, в значительной мере, именно в обеспечении непрерывной работы на ходу дорогостоящей части судна (машинного отделения) заключается эффективность работы ББС.

3. Для обеспечения лучших условий работы каждого типа ББС необходимо принимать во внимание следующие ограничивающие факторы, которые влияют на габаритные размеры и количество барж в составе, а, следовательно, и на грузоподъемность и мощность двигателя буксиpa:

- интенсивность грузовых работ в портах;

- максимально допустимые габариты судов для захода в порт, прохождения шлюзов, размеры извилистых участков трассы, а также участков прохождения под мостами;

- протяженность участка перехода.

Принимая интенсивность грузовых работ в портах погрузки и выгрузки в определенных портах величиной постоянной, варьировать можно только мощность двигателя и грузоподъемность баржи (комплекта барж).

4. Современные системы соединения барж и буксиров позволяют эксплуатировать ББС не только на речном участке, но и с выходом в море. Таким образом, район плавания также оказывает влияние как на конструктивные элементы судна, так и на количество барж в составе. Однако, в условиях морского плавания возможна лишь комбинация состава ББС, состоящего из одного буксира и одной баржи.

5. Предполагаемая методика действительна как при работе ББС с загрузкой только в одном направлении, при участии одного порта погрузки и одного порта выгрузки, так и с учетом обратного перехода с порожней баржей или с обратной загрузкой между двумя портами. При наличии обратного грузопотока необходимо учитывать общее время стоянок под погрузкой и выгрузкой по каждому порту.

Исходя из вышесказанного, сформулированы следующие методы эвристики, учет которых обеспечивает выбор схемы для работы ББС определенного типоразмера либо выбор типоразмера ББС для определенной схемы работы за счет рационального сочетания техникоэксплуатационных характеристик барж и буксиров: 
1. Лучшей является та схема, где нет простоя буксира в ожидании освобождения от грузовых операций баржи ( $t$ ожкс в(п) $)$, т. е. время ожидания буксиром освобождения баржи от погрузочно-разгрузочных работ стремится к нулю, либо должно быть минимальным, и задается границами:

$$
0 \leq t_{\text {ож }}^{\text {букс в(п) }} \leq d \text { букс },
$$

где $d^{\text {букс }}$ - величина, подлежащая обоснованию и определяемая соотношением доходов ББС от перевозки и расходов буксира на стоянке.

Иначе, время ожидания буксиром освобождения баржи от погрузочно-разгрузочных работ определяется по формуле:

$t \underset{\text { ож }}{\text { букс в(п) }=t} \underset{\mathrm{c}}{\text { барж в(п) }}-t \underset{\mathrm{x}}{\text { букс вниз(вверх) }}$

где $t \underset{\mathrm{x}}{\text { букс вниз(вверх) }}-$ ходовое время буксира вниз (вверх) к устью, сут; $t$ барж в(п) - время стоянки баржи под выгрузкой (погрузкой), сут;

При положительном значении $t$ - простой в порту отправления, при отрицательном - в порту назначения.

2. Лучшей является та схема, где нет простоя баржи в ожидании освобождения прихода буксира $(t \underset{\text { ож }}{\text { барж в(п) }})$, т. е. время ожидания баржей прихода буксира сводится к нулю. Таким образом, время простоя баржи сводится к нулю, либо должно быть минимальным для чего задается границами:

$$
0 \leq t \underset{\text { ож }}{\text { барж } \mathrm{B}(п)} \leq d \text { барж, }
$$

где $d^{\text {барж }}$ - величина, подлежащая обоснованию и определяемая соотношением доходов ББС от перевозки к расходам баржи на стоянке.

Иным способом, время простоя баржи в ожидании буксира определяется как

$$
t_{\text {ож }}^{\text {барж в(п) }=t} \begin{aligned}
& \text { барж п } \\
& \mathrm{c}
\end{aligned}
$$

или

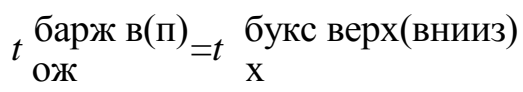

$$
\begin{aligned}
& -t \underset{\mathrm{c}}{\text { барж в(п) }+t} \begin{array}{l}
\text { букс в(п) } \\
\text { ож }
\end{array}
\end{aligned}
$$

где $t_{\mathrm{c}}^{\text {барж в(п) }}$ - время ожидания буксиром освобождения баржи от погрузочноразгрузочных работ в порту выгрузки (погрузки), сут; $t$ ож прихода буксира в порту выгрузки (погрузки), сут.

При положительном значении уравнения простой в порту отправления, при отрицательном - в порту назначения.

3. Интервал отправления ББС из порта отправления при рейдовой перегрузке должен быть равен времени стоянки баржи под выгрузкой в порту назначения:

$$
t_{\text {и }}=t \underset{\mathrm{c}}{\text { барж в }},
$$

где $t_{\text {и }}-$ интервал отправления ББС из порта отправления, сут.

4. Время кругового рейса грузового морского судна кратно целочисленному значению времени кругового (замкнутого) рейса буксира:

$$
t \underset{\mathrm{p}}{\mathrm{M} . \mathrm{c}}=a \times t \underset{\mathrm{p}}{\text { букс }},
$$

где $t_{\mathrm{p}}^{\mathrm{M} . \mathrm{c}}-$ время кругового рейса морского судна, сут; $t \underset{\mathrm{p}}{\text { букс }}-$ времени кругового (замкнутого) рейса буксира, сут; а - целочисленное значение, равное количеству ББС.

При этом время кругового рейса грузового морского судна определяется из выражения:

$$
\begin{aligned}
t \underset{\mathrm{p}}{\text { букс }}=t \underset{\mathrm{x}}{\text { букс низ }}+t \underset{\mathrm{x}}{\text { букс вверх }}+ \\
+t \underset{\text { ож }}{\text { букс в(п) }} .
\end{aligned}
$$

5. Время загрузки морского судна должно быть кратно целочисленному времени загрузки комплекта барж и определяется необходимым количеством комплектов барж для загрузки морского судна: 


$$
{ }_{n^{c}}{ }_{\text {барж }}=\frac{Q_{c}^{\text {мор }}}{Q^{\text {бар }}},
$$

где $Q_{c}^{\text {мор }}$ - максимально допустимая загрузка морского судна, $\mathrm{T} ; n^{c}$ барж - необходимое количество комплектов барж для загрузки морского судна; $Q^{\text {бар }}$ - максимально допустимая загрузка комплекта барж (максимально возможное количество груза, которое может быть принято на судно в данных условиях его работы), т.

Методика определения времени максимально допустимой загрузки комплекта барж, исходя из ограничений, изложена в работе [5]. По аналогии определяется максимально допустимая загрузка морского судна.

\section{Результаты}

Наглядно рассмотренные методы эвристики представлены в виде блок-схемы на рис. 1.

При решении каждого логического блока с положительным результатом (критерий $\mathrm{k}$ ) присваивается значение «+», с отрицательным (критерий g) - значение «-». Обработка результатов проводится по максимальному суммарному значению критерия $\mathrm{k}$. При равных результатах для нескольких ББС формируется график для этих типов ББС. Окончательный отбор судна производится по экономическим показателям. Исходя из решаемой в исследовании задачи, рассматриваются схемы $\ell$ и баржебуксирные суда типа $\mathrm{z}(\ell=\overline{1, \mathrm{~L}} ; \mathrm{z}=\overline{1, \mathrm{Z}})$.

\section{Научная новизна и практическая значимость}

Авторами впервые был применен эвристический подход к отбору баржебуксирных и морских судов для согласованной работы с выполнением грузовых операций на рейде устьевого порта. В основу подхода положен подбор рационального соотношения ТЭХ барж и буксиров. Предложенный подход позволяет определить наилучшее сочетание типоразмеров судов при организации совместной роботы морского и речного транспорта, тем самым обеспе- чивая непрерывность процесса перевозки грузов, следующих из морских портов в речные, расположенные в глубине страны (и в обратном направлении).

Полученные результаты будут применены в личных исследовательских разработках. Кроме того, представленное исследование может быть полезным для судоходных компаний, оперирующих баржебуксирным флотом, а также методика может быть внедрена в учебный процесс при изучении дисциплины «Основы теории транспортных процессов и систем (Организация работы флота)».

\section{Выводы}

В ходе рассмотренного исследования был проведен анализ литературных источников и выявлено следующее:

А. Исследования по рассматриваемой проблематике в отечественной литературе несколько устарели;

Б. Зарубежные исследования проводятся и широко освещаются преимущественно в направлениях:

1) ББП грузов в контейнерах в различных районах плавания;

2) технической реализации возможности эксплуатации ББС в различных путевых условиях.

В. Подтверждена актуальность темы исследования.

Рассматриваемая в статье задача входит в комплекс задач организации работы баржебуксирного флота.

Приведенный в работе эвристический подход к отбору судов для работы по схеме (схемам):

1) обеспечивает непрерывный процесс перевозки грузов по внутренним водным путям, минимизирует задержки судов в транзитных портах, обеспечивает регулярную подачу судов.

2) позволяет определить наилучшее сочетание количества технических средств при планировании роботы морского и речного транспорта.

В результате исследований составляется приоритетный ряд из типоразмеров ББС для работы на линии.

Дальнейшее развитие методики предполагает оценку целесообразности эксплуатации ББС типа $\mathrm{z}$ из приоритетного ряда на линии. 


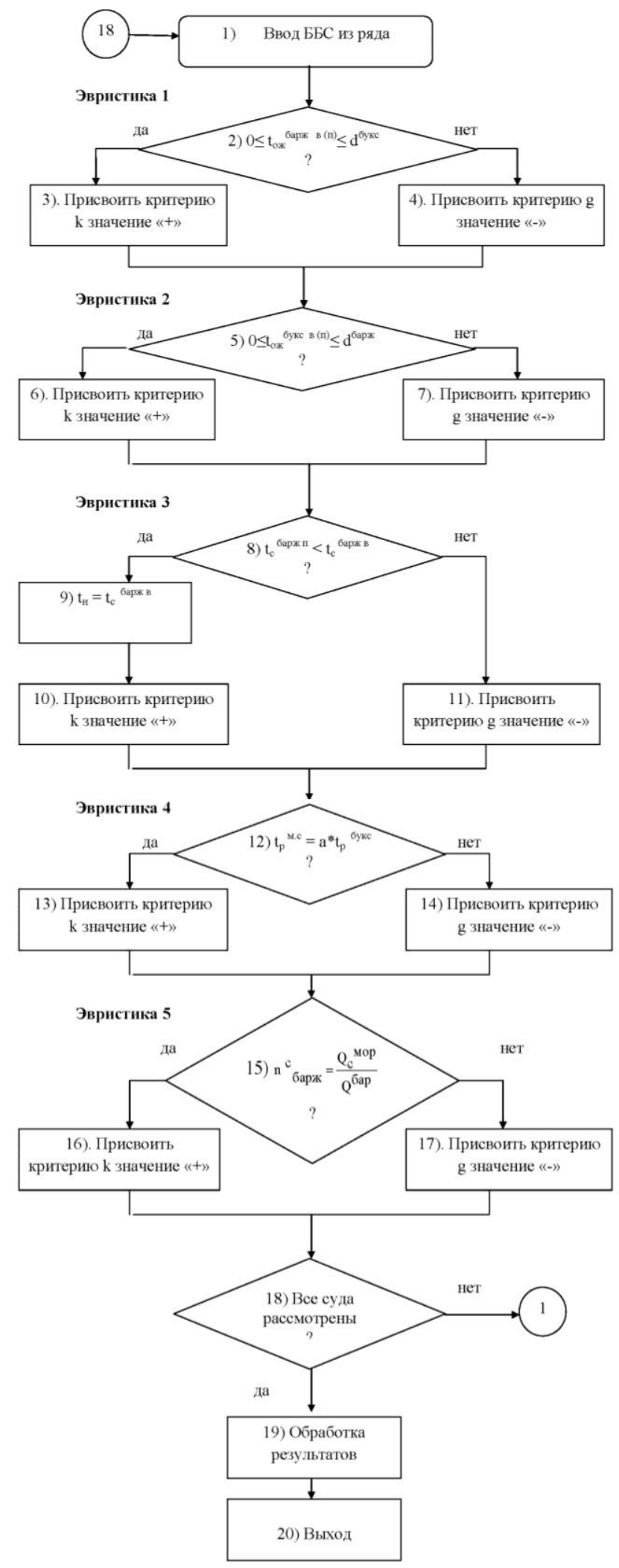

Рис. 1. Состав и последовательность операций отбора судов с помощью эвристического подхода

Fig. 1. Composition and sequence of ship selection operations using a heuristic approach 


\section{СПИСОК ИСПОЛЬЗОВАННЫХ ИСТОЧНИКОВ}

1. Сгоров, О. Г. Вибір оптимальних характеристик составних суден і барже-буксирних составів змішаного плавання : дис. ... канд. техн. наук : 05.22.19 / Сгоров Олександр Геннадійович ; Одес. нац. мор. ун-т. - Одеса, 2016. - 495 с.

2. Союзов, А. А. Внедрение разработок по оптимальному распределению буксирно-баржевого флота в советском дунайском пароходстве / А. А. Союзов, Е. С. Коврига // Экономика и эксплуатация морского транспорта : сб. науч. тр. - Москва, 1971. - Вып.8. - С. 24-35.

3. Трифонов, А. В. Концепция создания судов для комплексного освоения малых рек классов VIIa и VIIб : дис. ... канд. техн. наук : 05.22.19 / Трифонов Андрей Владимирович ; Моск. гос. акад. водн. трансп. - Москва, 2002. - 256 с.

4. Шибаев, А. Г. Подготовка и обоснование решений по управлению перевозками и работой флота морской судоходной компании : монография / А. Г. Шибаев. - Одесса : ХОРС, 1998. - 208 с.

5. Щербина, О. В. Определение типоразмера барже буксирного состава / О. В. Щербина // Вісн. Східноукр. нац. ун-ту ім. В. Даля. - 2017. - № 4 (234). - С. 248-253.

6. Щербина, О. В. Формування переваг використання барже буксирних суден для міжнародних перевезень українських експортних вантажів / О. В. Щербина, О. В. Акимова // Зб. наук. пр. SWord. - Одеса, 2015. - № 1 (38). - C. 19-24.

7. Циклическая работа [Электронный ресурс]. - Режим доступа: http://www.articouple.com/rus/20cyclic.html. - Загл. с экрана. - Проверено : 17.12.2017.

8. Caris, A. Modeling corridor networks in intermodal barge transport [Электронный pecypc] / A. Caris, C. Macharis, G. Janssens. - 2010. - Режим доступа: http://www.wctrs-society.com/wp/wpcontent/uploads/abstracts/lisbon/selected/01919.pdf. - Загл. с экрана. - Проверено : 17.12.2017.

9. Kaup, M. Functional model of river-sea ships operating in European system of transport corridors: Part I. Methods used to elaborate functional models of river-sea ships operating in European system of transport corridors / M. Kaup // Polish Maritime Research. - 2008. - Vol. 15. - Iss. 3. - P. 3-11. doi: 10.2478/v10012-007-0077-y.

10. Kaup, M. Functional model of river-sea ships operating in European system of transport corridors: Part II. Methods of determination of design assumptions for river-sea ships operating in European system of transport corridors, according to their functional model / M. Kaup // Polish Maritime Research. - 2008. Vol. 15. - Iss. 4. - P. 3-11. doi: 10.2478/v10012-007-0090-1.

11. Konings, R. Hub-and-spoke networks in container-on-barge transport / R. Konings // Transportation Research Record: Journal of the Transportation Research Board. - 2006. - Vol. 1963. - C. 23-32. doi: 10.3141/1963-04.

12. Malchow, U. Port Feeder Barge: Advanced Waterborne Container Logistics for Ports / U. Malchow // TransNav: Intern. Journal on Marine Navigation and Safety of Sea Transportation. - 2014. - Vol. 8. - Iss. 3. - P. 411-416. doi: 10.12716/1001.08.03.12.

13. Stoop, J. A. Safe and swift performance, a conceptual assessment of a new river sea pusher system / J. Stoop, M. B. Duinkerken // Intern. Conference on Safety and Operations in Canals and Waterways $\left(15-16^{\text {th }}\right.$ September 2008, Glasgow, UK) / University of Strathclyde and Glasgow. - Glasgow, 2008. - C. 50-59.

14. Ššskić, S. Analysis of River-Sea Transport in the Direction of the Danube-Black Sea and the Danube Rhine River Main / S. Šoškić, Z. Đekić, M. Kresojević // TransNav: International Journal on Marine Navigation and Safety of Sea Transportation. - 2014. - Vol. 8. - Iss. 4. - P. 523-531. doi: 10.12716/1001.08.04.06.

15. Wiegmans, B. W. Strategies and innovations to improve the performance of barge transport / B. W. Wiegmans, R. Konings // European Journal of Transport and Infrastructure Research (EJTIR). - 2007. - No. 2. P. 145-162.

\section{О. В. ЩЕРБИНА ${ }^{1 *}$, О. Г. ШИБАСВ ${ }^{2 *}$}

\footnotetext{
${ }^{1 *}$ Каф. «Експлуатація флоту і технології морських перевезень», Одеський національний морський університет, вул. Мечнікова, 34, Одеса, Україна, 65011, тел. + 38 (093) 05357 02, ел. пошта olahome@ rambler.ru, ORCID 0000-0001-5029-6098

${ }^{2 *}$ Каф. «Експлуатація флоту і технології морських перевезень», Одеський національний морський університет, вул. Мечнікова, 34, Одеса, Україна, 65011, тел. (048) 72831 24, ел. пошта cafmp@i.ua, ORCID 0000-0002-9886-6069
} 


\section{ЕВРИСТИЧНИЙ МЕТОД ВІДБОРУ СУДЕН ДЛЯ УЗГОДЖЕНОЇ РОБОТИ ВОДНОГО ТРАНСПОРТУ}

Мета. У даному дослідженні необхідно розглянути формування методики відбору суден при узгодженій роботі морського та річкового транспорту зі застосуванням евристичного підходу. Методика. Для реалізації поставленої у дослідженні мети авторами було проведено аналіз вітчизняних і зарубіжних літературних джерел за темою роботи, вивчено специфіку та визначено умови ефективної роботи морських монокорпусних та складених баржебуксирних суден. Результати. На підставі результатів аналізу були сформульовані методи евристики, що забезпечують вибір типорозмірів баржебуксирних суден змішаного плавання «рікаморе» 3 пріоритетного ряду суден наявного флоту. Запропонований підхід дозволяє виконати відбір суден, що в більшій мірі відповідають встановленій схемі роботи. Раціональні поєднання техніко-експлуатаційних характеристик таких пар, як «баржі і буксир», «баржебуксирне судно і морське судно», «баржебуксирне судно і характеристики, що обмежують район плавання», $є$ передумовою до збільшення прибутку судноплавної компанії за рахунок збільшення провізної здатності суден. Наукова новизна. Авторами вперше був застосований евристичний підхід до відбору баржебуксирних та морських суден для узгодженої роботи 3 виконанням вантажних операцій на рейді гирлового порту при перевезенні масових вантажів. В основу підходу покладено підбір раціонального співвідношення техніко-експлуатаційних характеристик барж і буксирів. Запропонований підхід дозволяє визначити оптимальне поєднання типорозмірів суден при організації спільної роботи морського та річкового транспорту. При цьому забезпечується безперервність процесу перевезення вантажів, що прямують із морських портів у річкові, розташовані в глибині країни (і в зворотному напрямку). Практична значимість. Представлена методика $є$ логічним продовженням циклу робіт, виконаних авторами. Отримані результати також будуть застосовані в наступних особистих дослідних розробках. Крім того, представлене дослідження буде корисним для судноплавних компаній, що оперують баржебуксирним флотом. Також дана методика може бути впроваджена в навчальний процес транспортних вищих навчальних закладів при вивченні відповідних дисциплін.

Ключові слова: морські та баржебуксирні судна; рейдове перевантаження; відбір; евристичний підхід

\section{O. V. SHCHERBINA ${ }^{1 *}$, A. G. SHIBAEV ${ }^{2 *}$}

\footnotetext{
${ }^{1 *}$ Dep. «Fleet Operation and Technology of Sea Transportations», Odessa National Maritime University, Mechnikov St., 34, Odessa, Ukraine, 65011, tel. +38 (093) 05357 02, e-mail olahome@ rambler.ru, ORCID 0000-0001-5029-6098

$2^{2 *}$ Dep. «Fleet Operation and Technology of Sea Transportations», Odessa National Maritime University, Mechnikov St., 34, Odessa, Ukraine, 65011, phone: +38 (048) 72831 24, e-mail cafmp@i.ua, ORCID 0000-0002-9886-6069
}

\section{HEURISTIC METHOD OF SHIPS SELECTION FOR THE COORDINATED WORK OF WATER TRANSPORT}

Purpose. The study aims to develop a formulation methodology for ship selection in the coordinated work of sea and river transport using a heuristic approach. Methodology. To realize the purpose set in the study, the authors carried out an analysis of domestic and foreign literature sources on the current topic, studied specifics and conditions for the effective operation of marine mono-hulled ships and composite tug/barge towing ones. Findings. The analysis results allowed formulating the heuristics methods that ensure the selection of the type sizes of tug/barge towing ships for the mixed «river-sea» navigation from the priority range of ships of the existing fleet. The proposed method makes it possible to select ships in a more appropriate manner according to the established scheme of work. Rational combinations of technical and operational characteristics of such pairs as «barges and tows», «tug/barge towing ship and sea-going ship», «tug/barge towing ship and restrictive characteristics of the area of navigation» are a prerequisite for the shipping company profit growth by increasing the capacity of ships. Originality. For the first time, the authors applied a heuristic approach to the selection of tug/barge towing ships and sea-going ones for coordinated work with the performance of cargo operations on the raid of the estuary port when transporting bulk goods. The basis of the approach is the selection of a rational mix of technical and operational characteristics of barges and tugs. The proposed approach allows determining the best combination of ship type sizes in the organization of coordinated work of sea and river transport. At the same time, the continuity of the goods transportation process from the sea ports to the river ones located in the depth of the country (and in the opposite direction) is ensured. Practical value. The presented methodology is a logical continuation of the cycle of studies performed by the au- 
thors. The obtained results will also be applied in subsequent personal research developments. In addition, the presented research may be useful for shipping companies that run the tug/barge towing fleet. The presented methodology may also be introduced into the learning process of transport higher education institutions in the study of relevant disciplines.

Keywords: sea-going and tug/barge towing ships; raid overload; selection; heuristic approach

\section{REFERENCES}

1. Yegorov, O. H. (2016). Vybir optymalnykh kharakterystyk sostavnykh suden i barzhe-buksyrnykh sostaviv zmishanoho plavannia. (Dysertatsiia kandydata tekhnichnykh nauk). Odessa National Maritime University. (in Ukranian)

2. Soyuzov, A. A., \& Kovriga, Y. S. (1971). Vnedreniye razrabotok po optimalnomu raspredeleniyu buksirnobarzhevogo flota v sovetskom dunayskom parakhodstve. Ekonomika i ekspluatatsiya morskogo transporta, 8 , 24-35. (in Russian)

3. Trifonov, A. V. (2002). Kontseptsiya sozdaniya sudov dlya kompleksnogo osvoeniya malykh rek klassov VIIa $i$ VIIb. (Dissertatsiya kandidata tekhnicheskikh nauk). Moscow State Academy of Water Transport. (in Russian)

4. Shibayev, A. G. (1998). Podgotovka i obosnovanie resheniy po upravleniyu perevozkami i rabotoy flota morskoy sudokhodnoy kompanii: Monografiya. Odessa: KhORS. (in Russian)

5. Shcherbina, O. V. (2017). Opredelenie tiporazmera barzhe buksirnogo sostava. Visnyk Skhidnoukraiskoho natsionalnoho universytetu im. V. Dalia, 4(234), 248-253. (in Russian)

6. Shcherbyna, O. V. \& Akymova, O. V. (2015). Formuvannia perevah vykorystannia barzhe buksyrnykh suden dlia mizhnarodnykh perevezen ukrainskykh eksportnykh vantazhiv. Zbirnyk naukovykh prats SWord, 1(38), 19-24. (in Ukranian)

7. Tsiklicheskaya rabota. Retrived from http://www.articouple.com/rus/20-cyclic.html. (in Russian)

8. Caris, A., Macharis, C., \& Janssens, G. (2010). Modelling corridor networks in intermodal barge transport. Retrieved from http://www.wctrs-society.com/wp/wp-content/uploads/abstracts/lisbon/selected/01919.pdf. (in English)

9. Kaup, M. (2008). Functional model of river-sea ships operating in European system of transport corridors: Part I. Methods used to elaborate functional models of river-sea ships operating in European system of transport corridors. Polish Maritime Research, 15(3), 3-11. doi: 10.2478/v10012-007-0077-y. (in English)

10. Kaup, M. (2008). Functional model of river-sea ships operating in European system of transport corridors: Part II. Methods of determination of design assumptions for river-sea ships operating in European system of transport corridors, according to their functional model. Polish Maritime Research, 15(4), 3-11. doi: 10.2478/v10012-007-0090-1. (in English)

11. Konings, R. (2006). Hub-and-spoke networks in container-on-barge transport. Transportation Research Record: Journal of the Transportation Research Board, 1963, 23-32. doi: 10.3141/1963-04. (in English)

12. Malchow, U. (2014). Port Feeder Barge: Advanced Waterborne Container Logistics for Ports. TransNav: International Journal on Marine Navigation and Safety of Sea Transportation,8(3), 411-416. doi: 10.12716/1001.08.03.12. (in English)

13. Stoop, J. A., \& Duinkerken, M. B. (2008). Safe and swift performance, a conceptual assessment of a new river sea pusher system. International Conference on Safety and Operations in Canals and Waterways, 50-59. (in English)

14. Šoškić, S., Đekić, Z., \& Kresojević, M. (2014). Analysis of River-Sea Transport in the Direction of the Danube-Black Sea and the Danube Rhine River Main. TransNav: International Journal on Marine Navigation and Safety of Sea Transportation 8(4), 523-531. doi: 10.12716/1001.08.04.06. (in English)

15. Wiegmans, B. W., \& Konings, R. (2007). Strategies and innovations to improve the performance of barge transport. European Journal of Transport and Infrastructure Research (EJTIR), 2, 145-162. (in English)

Статья рекомендована к публикации д.т.н., проф. В. П. Сторожевым (Украина); д.т.н., проф. Д. Н. Козаченко (Украина)

Поступила в редколлегию: 09.10.2017

Принята к печати: 08.01.2018 